\title{
Small Historical Centres:
} an opportunity for the "smart" revitalization of Inner Areas in the Post (post) COVID Era

\author{
Mario Cerasoli \\ mario.cerasoli@uniroma3.it | (D) orcid.org/0000-0001-5891-4049 \\ Department of Architecture, Roma Tre University
}

Scientific Editor: Carlos Marmolejo Duarte, Polytechnic University of Catalonia Technical Editor: Aleksandra Urzędowska, Cracow University of Technology Press Language Editor: Tim Churcher, Big Picture Typesetting: Matgorzata Murat-Drożyńska, Cracow University of Technology Press

Received: September 25, 2020

Accepted: April 10, 2021

Copyright: @ 2021 Cerasoli. This is an open access article distributed under the terms of the Creative Commons Attribution License, which permits unrestricted use, distribution, and reproduction in any medium, provided the original author and source are credited.

Data Availability Statement: All relevant data are within the paper and its Supporting Information files.

Competing interests: The authors have declared that no competing interests exist.

Citation: Cerasoli, M. (2021). Small Historical Centres: an opportunity for the "smart" revitalization of Inner Areas in the Post (post) COVID Era. Technical Transactions, e2021005. https://doi.org/ 10.37705/TechTrans/e2021005

\begin{abstract}
The Pandemic is forcing everyone to become aware of the need for a change in the cultural and socio-economic paradigms of recent decades.

During the twentieth century, on the one hand, entire populations concentrated in urban areas with ever higher population densities, at the same time giving rise to the phenomenon of "urban sprawl" or "suburbanization".

On the other hand, entire territories have been abandoned (the so-called "inner areas").

Now, we can define territorial rebalancing strategies based precisely on the reactivation of "inner areas". Strategies that, in the Post (post) COVID era will have to be not only resilient, but anti-fragile. And the key is precisely in the future of the smaller historical centres.

This article aims to review the strengths and weaknesses of small historic centres, outlining possible scenarios for their "smart" revitalization and for a true sustainable and inclusive development.
\end{abstract}

Keywords: Small Historical Centres, Inner Areas, urban recovery, "smart" revitalization, Post (post) COVID Era 


\section{Introduction}

In recent months, we have experienced a dramatic global health emergency caused by the spread of the COVID-19 virus. This is forcing us to become aware of the need for a change in the cultural and socio-economic paradigms to which we have been accustomed in last decades.

Maybe we are finally beginning to realize, quoting the Pope Francis' words for the Extraordinary Universal Prayer for the end of the Covid-19 Pandemic, on March 27,2020 , that "one cannot think of always remaining healthy in a sick world".

And the "disease" of the contemporary world is called unsustainable development, individualism (not liberalism), social exclusion, uncontrolled exploitation of natural resources, lack of respect for the planet where we live.

Greedy for profit, we let ourselves be absorbed by things and bewildered by haste. We did not stop in front of Your calls, we did not wake up in the face of planetary wars and injustices, we did not listen to the cry of the poor, and of our seriously ill planet (Pope Francis).

During the Twentieth, pursuing perhaps arrogant development models, we left that entire populations were concentrated in urban areas with more and more extreme density ${ }^{1}$ or consume large territories with the phenomenon that in the sixties was called "urban sprawl" or more recently "suburbanization"2.

But, at the same time, we allowed the abandonment of entire territories (the so-called "inner areas") and, with them, all those activities linked to the territory and its care, activities that have guaranteed its livelihood for centuries.

The senseless - and irresponsible - exploitation of natural resources and the pollution caused by the use of fossil fuels are producing increasingly sensitive effects on the climate and on our planet's ability to defend itself. Moreover, the unbridled race towards ephemeral consumerism is causing more and more an intolerable production of waste, which are solid but also increasingly social.

Starting from the experience of the Pandemic, from the understanding of what is really necessary, now we can't help but decide to undertake - certainly not fast - a path that should lead us to change many things in the societies in which we live, starting with demolition of some - now globalized - cultural stereotypes.

The aim of this paper is to demonstrate that recovery and urban regeneration can become the main modes of intervention, expression of a renewed approach to the existing city, especially the historical one. For this purpose, firstly a radical revision of the mobility models is necessary. Mobility must urgently be oriented towards true forms of sustainable transport, redefining modal hierarchies, giving centrality to pedestrians, bicycles and public transport and outlining a future scenario that is not based (only) on the autonomous electric car, but on innovative public transport systems, such as the guided optically bus ("trackless trams") or on automatic centrally controlled trains.

Faced with the need to rediscover the concept of "proximity", it is necessary to reorganize our cities and our territories with the aim of reducing, if not eliminating, the plethora of unnecessary but mandatory daily trips.

We now have the rare opportunity to contribute to outline strategies for the rebalancing of the territory, based precisely on the reactivation of the "inner areas" and small historical centres.

\footnotetext{
A recent research has shown that if the entire territory of Argentina (surface 2,780,403 sq km, population $43,432,376)$ were built with the same density as the city of Buenos Aires (14,450 inhabitants/sq km in the Federal Capital, population 3,068,043 inhabitants), we could host more than five times the entire world population, which is 7,789,000,000 inhabitants.

2 The "suburbanization" is a phenomenon that has spread since the 60s of the last century - when Jane Jacobs denounced its dangers - and that has generated a breaking point with the traditional European city. In other words, it marked the transition from the compact city, an expression of formal continuity, to that dominated by fragmentation, characteristic of the "diffuse metropolis", characterized by low population density, monofunctionality, lack of public space and attractiveness. aesthetic, the impoverishment of the landscape, the lack of "urban quality".
} 
Strategies that, in the Post (post) COVID era, when we return to a "new" normality, will have to be not only resilient, but anti-fragile (Taleb, 2013; Blecic \& Cecchini, 2016). The recovery of the "values" of the territory must be understood as the reconstruction of the economic layout necessary to reactivate the peripheral territories.

And the key is precisely in the future of the small historical centres (which seems an oxymoron).

This paper refers to some of the most recent results of a ten-year research program on the "small historical centres" (Cerasoli, 2010), carried out at the Department of Architecture of the "Roma Tre" University, and in particular address the issues of "Inner Areas" and small historical centres, reaching out a "smart" scenario for their post (post) COVID future.

\section{Small Historical Centres and Inner Areas: what are we talking about?}

The small or minor historical centres are the original nucleus of those small and very small cities, which, in general, form the Italian urban heritage of the "inner" or "peripheral" areas. These territories have, on the one hand, critical issues related to accessibility to primary services (transport, education, health) but, at the same time, boast the presence of important cultural (archaeological heritage, historical settlements, abbeys, small museums, small centres of trade) and environmental resources (water, agricultural systems, forests, natural and anthropic landscapes). Also, they have a widespread distribution throughout the territory that reminds us of an ancient "network" of cities.

"Minor historical centres" are mentioned for the first time during the $6^{\text {th }} \mathrm{ANCSA}^{3}$ Conference, held in Bergamo in 1971. Alberto Predieri, in his speech, presented a classification of historical centres, dividing them into "historical centres of large metropolitan areas", "minor historical centres" and "abandoned minor historical centres". In defining the seconds, Predieri spoke of historical centres "inserted in rapidly developing cities or even stationary ones, originally locations of important political-cultural functions and economically carried out in areas of which they constitute the nodal points, now decayed, but of great historical, artistic, environmental and possibly tourist-cultural interest" (Seassaro, 1973).

Pier Luigi Cervellati, in 2009, divided the "minor historical centres" into three macro categories: the historic urban settlements "encapsulated" in expansion of cities and in the industrialized agriculture (i.e. those that have been "enveloped" by the growth of the so-called "city- region", as he himself had already defined the urbanized continuum that surrounded large cities in 1962); the historical urban settlements "abandoned" for natural reasons, often catastrophic, or for the construction of new settlements; and the historical settlements "transfigured" by the homologating recovery caused by tourism. A classification still valid today, which can also be enriched with other parameters. Like the "dimensional" ones.

According to ISTAT and ANCI (National Association of Italian Municipalities), minor centres are those municipalities that have a population of less than 5,000 inhabitants and among them we can identify the "minor historical centres".

In Italy, 5,495 municipalities out of the total 7,903 municipalities have a population of less than 5,000 inhabitants (3,474 less than 2,000, 1,964 less than 1,000 and 869 less than 500)4. Overall, in these municipalities, which represent $69.5 \%$ of the total and cover a territory that corresponds to $54 \%$ of the total of Italy, $16.2 \%$ of the national population lives.

In 1861 they were $88.5 \%$ of the total municipalities and $49.7 \%$ of the total national population lived there. Overall, the economy was poorer, but the territory was more balanced.

\footnotetext{
3 ANCSA is the National Association of Historical and Artistic Centres (Associazione Nazionale Centri Storici e Artistici).

4 Source: ISTAT, National Institute of Statistics, 2020.
} 


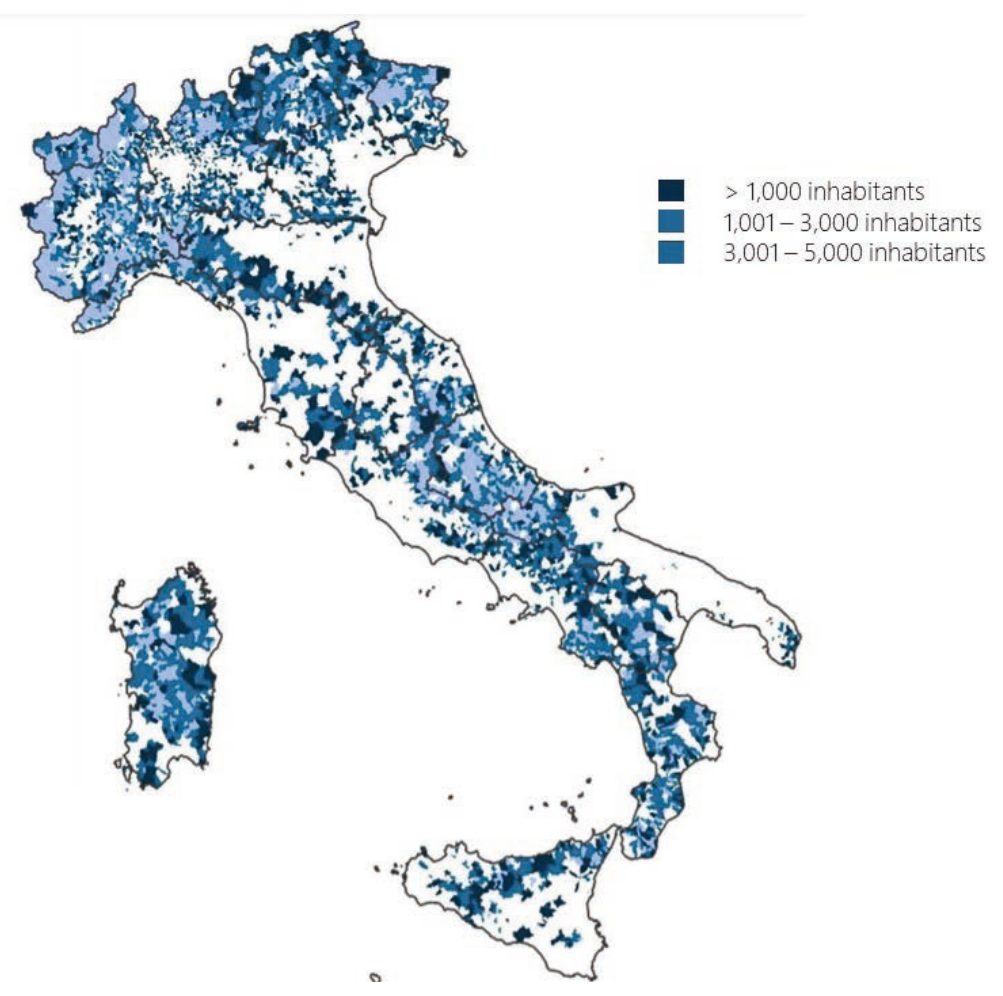

It is clear then that recovering their (historical) function of territorial protection from a socio-economic and environmental point of view is very fundamental today.

In the meantime, let us take a quick review of what Inner Areas are.

To better understand the complexity of these territories, it must be remembered that in 2014 the Agency for Territorial Cohesion, through the National Inner Areas Strategy (on the initiative of the then Minister for Territorial Cohesion, Fabrizio Barca), identified three classes of "peripheral” municipalities, depending on the travel time $(t)$ needed to reach the urban centres (ie "service provider centres", where there are "an adequate secondary school offer, a level 1 hospital ${ }^{5}$ and a "silver" railway station"):

- Intermediate areas: 20 minutes $<t<40$ minutes,

- Peripheral areas: 40 minutes $<t<75$ minutes,

- Ultra peripheral areas: $t>75$ minutes.

5 Hospitals, according to their importance, are classified into the following 3 categories:

- Basic hospital facilities (catchment area 80,000-150,000 inhabitants), equipped with First Aid and the following specialties: Internal Medicine, General Surgery, Orthopedics, Anesthesia and support services in the active guard network and/or in a ready availability regime on 24 hours (h.24) of Radiology, Laboratory, Blood Bank. They must also be equipped with "Intensive Short Observation" beds;

- First level hospitals (catchment area 150,000-300,000 inhabitants), equipped with the following specialties in addition to those present in the basic aids: Obstetrics and Gynecology (if required by number of births/year), Pediatrics, Cardiology with Intensive Care Unit Cardiology (UTIC), Neurology, Psychiatry, Oncology, Ophthalmology, Otolaryngology, Urology;

- Second level hospitals (catchment area 600,000-1,200,000 inhabitants), equipped with secondlevel First Aid and facilities that also cover the most complex disciplines (Source: Ministry of Health).

6 The railway stations, according to their importance, are divided into the following 4 categories:

- PLATINUM: includes railway stations characterized by very high attendance ( $>$ about 25,000 average visitors/day) and high quality passenger services for long, medium and short distances, including the High Speed railway;

- GOLD: includes medium / large railway stations characterized by high attendance ( $>10,000$ average visitors/day approximately) and high quality passenger services for long, medium and short distances;

SILVER: includes medium/small railway stations, often unattended, dedicated solely to regional/ metropolitan transport services and characterized by high and consistent attendance (in some cases $>$ 4,000 average visitors/day), or stations and stops characterized by frequentation consistent $(>2,500$ average visitors/day approximately) and services for long, medium and short distances;

- BRONZE: includes small railway stations and stops characterized by low attendance (generally $<500$ average visitors/day), often unattended, dedicated solely to regional/local traffic.
Fig. 1. Small municipalities $(<5,000$ inhabitants) in Italy (Source: ANCI research based on: ISTAT, National Institute of Statistics, 2017) 


\section{口:: technical

Table 1. Inner Areas classification (Source: Agency for Territorial Cohesion, National Strategy for Inner Areas; ISTAT, National Institute of Statistics, 2014)

\begin{tabular}{|c|c|c|c|c|}
\hline & Population & $\%$ & Area $(\mathrm{km} 2)$ & $\%$ \\
\hline ITALY & 59.433 .744 & 100 & $302.072,84$ & 100 \\
\hline MAIN URBAN AREAS & 46.104 .994 & 77,6 & $121.535,21$ & 40,3 \\
\hline INNER AREAS & 13.328 .750 & 22,4 & $180.537,63$ & 59,7 \\
\hline Intermediate areas & 8.832 .422 & 66,3 & $88.187,28$ & 48,8 \\
\hline Remote areas & 3.812 .271 & 28,6 & $72.829,47$ & 40,3 \\
\hline Ultra areas & 684.057 & 5,1 & $19.520,88$ & 10,8 \\
\hline
\end{tabular}

Fig. 2. Inner Areas classification (Source: Agency for Territorial Cohesion, National Strategy for Inner Areas; ISTAT, National Institute of Statistics, 2014)

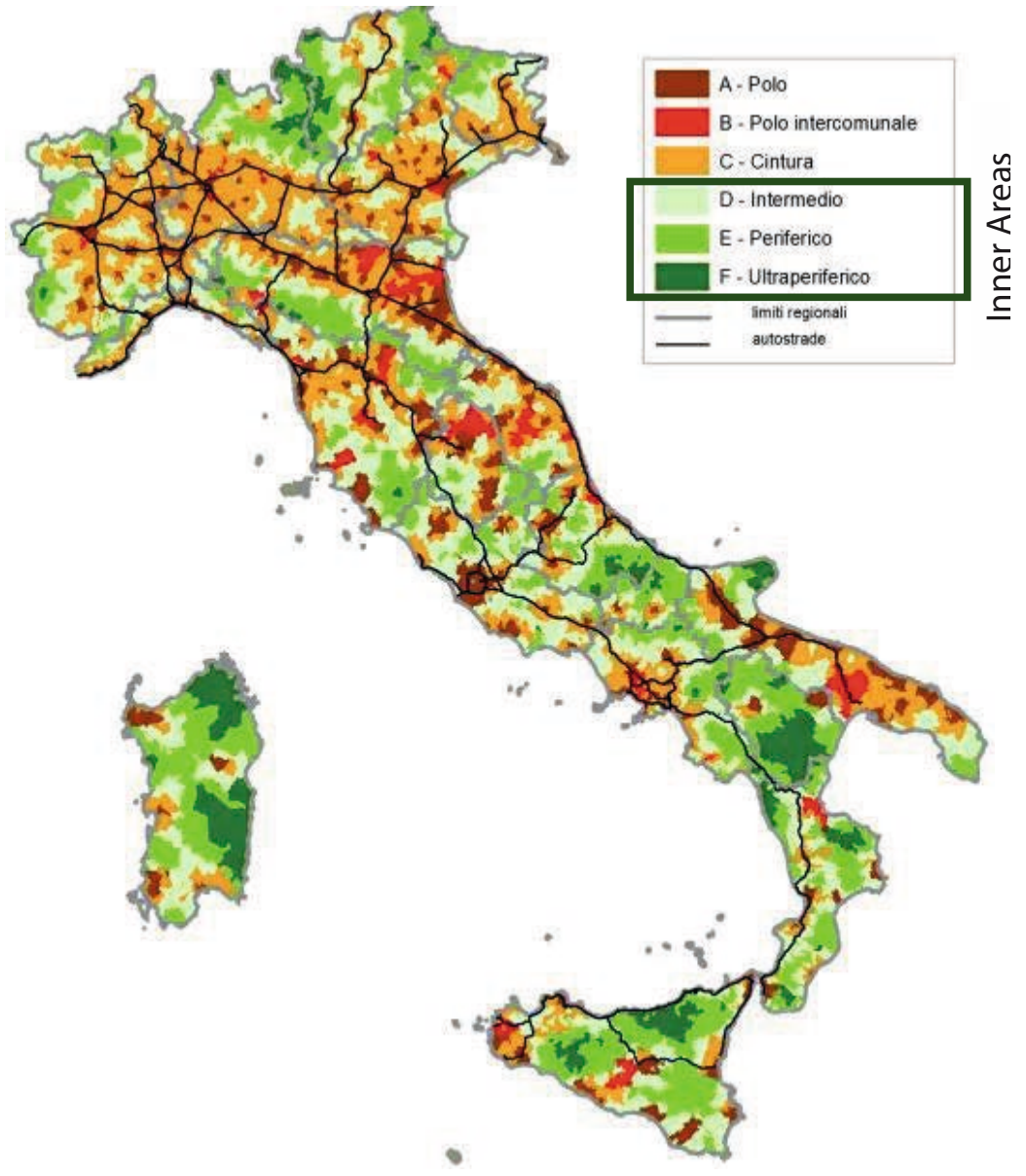

Currently, $59.7 \%$ of the national territory is an "inner area”, where however only $22.4 \%$ of the total population lives. Confirming the substantial coincidence with the "minor centres".

A series of causes can be cited which, independently or combined, have determined the progressive abandonment of the smaller urban centres, "producing" the inner areas.

The urbanism determined by the Industrial Revolution (a very late phenomenon in Italy) is among the most important of these causes, causing the migration to the large cities where the industries were located. But this cannot be analysed separately from the progressive decline of economic activities directly linked to the territory (agriculture, first). These activities, that was already in great suffering in the first decades of the twentieth century, suffered a very heavy crisis in the aftermath of the end of the Second World War. In fact, in 1950 the Agrarian Reform was approved (Law no. 841/1950), but this determined contrary effects to the set objectives, contributing above all to the pulverization of land property - without having previously and everywhere built effective cooperative mechanisms and consortium practices capable to 
maintain the solidity of production and compensate for the small size of the land once removed from the large estates.

The Wars, both the First and the Second, and some natural disasters (earthquakes, floods) complete the picture of the causes of the abandonment.

A picture that is at the basis of the progressive exodus of the active population from the "peripheral areas" to large urban areas or even abroad, in search of better living conditions and a better future. An exodus never really opposed by national policies, which, on the contrary, often contributed to the reduction of investments in those territories, diverted to large urban centres, with the exponential worsening of living conditions.

\section{Strengths and weaknesses of the small historical centres}

The historical centres, mainly the smaller ones, are today a resource of inestimable value, especially considering the experience that the Pandemic will leave.

As part of a research that I have been conducting for some years at the Department of Architecture of the Roma Tre University, the strengths that characterize the smaller historical centres have been identified; they are:

- intrinsic urban quality: the historical urban fabric, product of ancient knowledge and the action of time, combines elements of urban quality rarely present in contemporary cities; these places express "beauty";

- quality of the minor building heritage: in the historical centres not only the "nodal" buildings (churches, noble palaces, other specialized buildings) have indisputable characteristics of architectural quality but also the minor architectural heritage, the "poor" one, both in terms of construction techniques and aesthetic values; even more, they boast significantly better energy performance than equivalent recent buildings (especially those built during the various waves of real estate speculation), and, even with all due caution, can more easily made energetic efficient;

- dimension on the "human scale" (interpersonal relationships, neighbourhood strength, general safety): historical centres were born and have always developed following very precise rules regarding their growth, based on the needs of man - and not of the car; numerous studies have recognized minor historical centres as those places where social cohesion is significantly higher (we know each other, we help each other);

- general environmental quality: the city-countryside relationship in these contexts has always centred on a great respect between man and nature, linked to the awareness that people's livelihood comes first from the territory;

- widespread distribution throughout the territory: the network of small and very small municipalities has its origins in Italian history and tradition and has always represented the most effective control mechanism on the territory, guaranteeing its safety and correct and balanced use - not "exploitation".

At the same time, as result of the dynamics mentioned above, today we can identify a series of criticalities referable to all historical centres:

- abandonment by traditional inhabitants (forced or spontaneous);

- reduction of public services and reduction or disappearance of economic activities (traditional and non, both inside the inhabited areas and especially around);

- excess of tourism (wild touristification), seasonalisation of the local economy; or lack/absence of tourism;

- incompatible vehicle mobility (due to the characteristics of the road network) or even critical (due to the massive use of private vehicles due to the total absence of alternatives - and political will);

- difficult or critical accessibility, due to marginalization with respect to primary infrastructures or mobility flows; 
- degradation of buildings/degradation of public space;

- exposure to natural risks (caused by the progressive poor maintenance of buildings, public spaces and territory);

- replacement of traditional inhabitants with new ones (immigrants, attracted by the offer of low-cost housing), in the historical centres around the large urban areas;

- social degradation/absence of sense of belonging/tensions between social or ethnic groups;

- gentrification (redevelopment and renewal of city areas or neighbourhoods, with a consequent increase in the price of rents and properties and migration of the original inhabitants to other urban areas ${ }^{7}$ ).

\section{The potential of small historical centres: a "smart" scenario?}

Today the historical centres (minor and not) can play a decisive role in the rebalancing of the territory, reversing those trends (now also historical) to urban concentration and metropolitan suburbanization.

The Pandemic and the consequent lockdown made us personally experience the contradictions of our big cities, where people have become accustomed to living in contexts that have often subordinated the comfort and quality of public space, housing and workplaces to speculative interests ${ }^{8}$.

At the same time, the Pandemic has suddenly made rediscover the smaller towns. In recent months, Italian starchitects and authoritative academics have spoken out in their favour and many people have left the big cities to settle - temporarily - in the small villages, chosen as the "best place to smart work". But in order to truly relaunch small historical centres and Inner Areas also in the post (post) COVID era, it is necessary to activate coherent and effective policies and strategies that aim to revive local economies and traditional activities in a modern key, rediscovering the values of Agriculture and Nature, tracing the memories of the Past and enhancing the immense cultural heritage offered by these Places.

Never the return to the practice of "protection" of the territory has seems more opportune, feasible and very necessary as today.

The Post Post-Covid scenario (i.e. when we will return to normality) will be in the midst of the "fourth industrial revolution", in fact in a post-industrial era.

It will then be necessary to realize that the combination of "big city" and industry has long since disappeared. Industries were located on the edge of cities to ensure accessibility, energy sources and labour, thus determining their growth, often impetuous and uncontrolled - it is enough to observe what happened, for example, in large Latin American cities, where, at a certain moment, the migratory flows from the immense rural areas towards the big cities could no longer be contained, giving rise to the phenomenon of marginal and precarious housing.

On the other hand, the (few) large industries are already located far from the big cities, in areas that are increasingly specialized and at the same time highly qualified - also in environmental terms - and very well connected to infrastructure networks. However, even if the "need" to move from small towns to live in the big city is nowadays out of date, because industrial production is no longer concentrated there, large urban areas continue to attract inhabitants, for whom they only provide services, growing parasitically and thus feeding a vicious circle "more inhabitants - larger urban dimensions - more inhabitants".

We currently live in the technological age and physical "proximity" is no longer essential for all the activities of our daily life: within a few days, during

\footnotetext{
Definition translated from the original of the Treccani Dictionary of the Italian Language.

8 These are precisely the same interests that Fiorentino Sullo, then Minister of Public Works, tried to fight in 1963 with his urban reform proposal, unfortunately never approved.
} 


\section{口::: technical

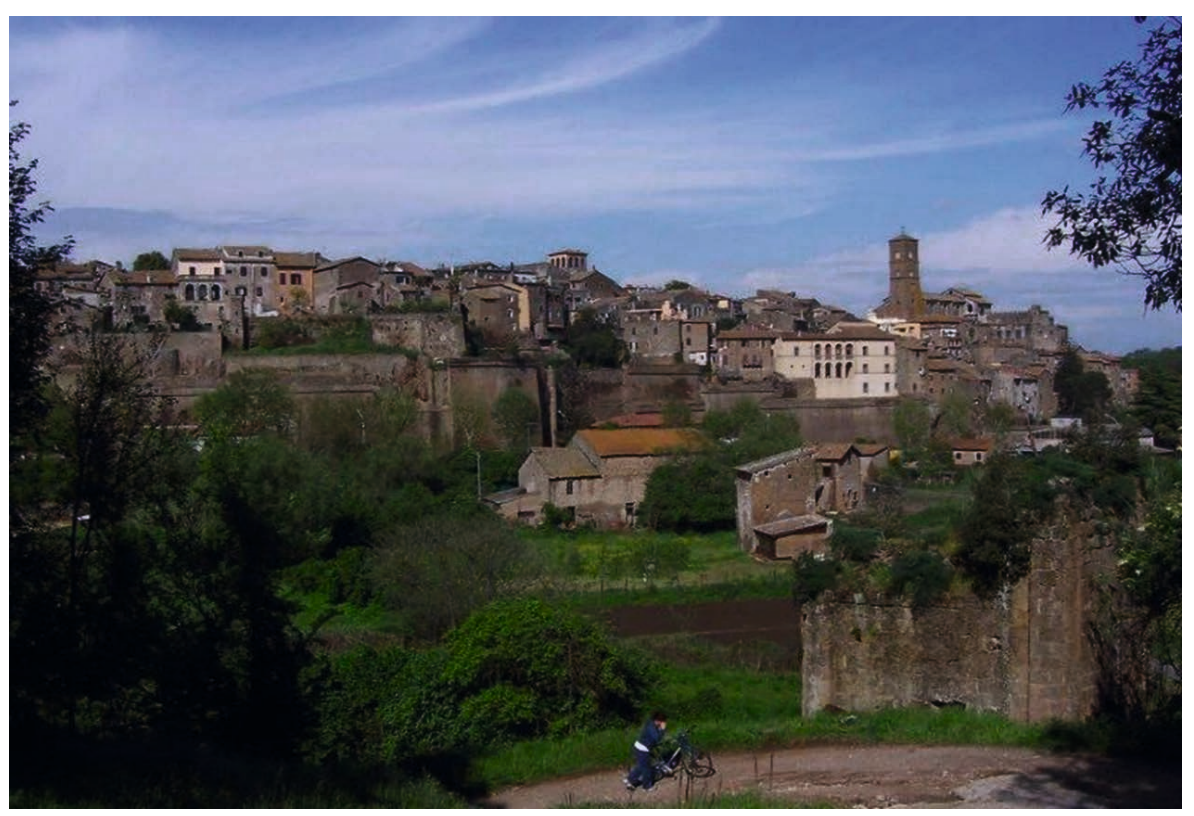

the last month of March, we "discovered" that we are now all connected (some better and some worse) in a global virtual network that has guaranteed many things (from work to leisure).

In this conjuncture, the opportunities offered by new technologies to the small historical centres are immense and can therefore be summarized as follows:

- improvement of integrated mobility management (smart public transport and private mobility, monitoring systems for infrastructures, traffic, parking, etc.);

- possibility of transforming mobility models, moving users from private transport to public or shared transport (which can be efficient, effective, comfortable and above all safe), reducing commuting (through the greater diffusion of teleworking and the redistribution of economic activities) and compulsory "useless" trips (by the stimulation of local economic activities and the better distribution of public services to citizens and tourists);

- overall improvement of environmental quality (reduction of pollutants) and urban safety (including through the use of smart lighting systems);

- improving the offer of public services to citizens and tourists;

- urban energy autonomy (micro and mini production and recycling plants) and intelligent management of the waste cycle;

- improvement of the quality of the residential and non-residential building heritage (building recovery/renewal, energy efficiency, domotics, etc.), compatibly with the "historical" characteristics ("modulation of protection" in urban recovery ${ }^{9}$ );

- remote monitoring of buildings and public spaces (state of conservation of the building heritage, real-time register of building transformations, aimed at mitigating natural and anthropogenic risks);

- participation and collaborative management in city government and urban transformation processes.

In this context, the Right to Mobility and Accessibility have fundamental importance and must therefore be accompanied by the redesign of movements and infrastructures. It is necessary to reduce, if not eliminate, the "useless compulsory mobility" (movements to concentrated commercial structures or to service centres or other territorial facilities that have replaced commerce and widespread services in the urban fabric), at the same time rebalancing the
Fig. 3. Sutri (Viterbo), historical centre (Photo by Author, 2018)

About “modulation of protection” see: Cerasoli, Biere Arenas, 2016. 
territory (through the redistribution of services and the relaunch of integrated and sustainable economic activities) and by encouraging forms of shared and smart mobility (private-public-soft integrated transport modes, "on-demand" transport, etc. $)^{10}$.

Small historical centres are the cities of fifteen minutes walking, often even less time!

\section{Conclusion}

In this context, it is essential to refer also to the "degrowth" movement, launched by the economic philosopher Serge Latouche, which would seem to be very suitable for the theme of small historical centres. The theory of "degrowth" has been disseminated in order to contrast the misleading use of the concept of "sustainable development" and the - now perverse - logic of a growing society. Taking as example the "wisdom of the snail", degrowth, for Latouche, becomes a "password to strongly indicate the need to abandon the foolish goal of growth for growth, ... whose only engine is the search for profit. by those who own the capital" (Latouche, 2006) ${ }^{11}$.

Degrowth is an extremely interesting "thought", in many ways acceptable, as it is evident that one cannot continue to speak of "development" in an almost pathological way, but that it has nothing sustainable (the Earth is a finite system that it needs time to replenish stocks and we cannot think in an infinite growth).

But the theory of degrowth continues to fail to identify the strategies to be adopted in "peripheral" territories as well as in developing countries: how can one "decrease" when the "growth" has not yet been achieved?

Rather than "degrowth", as an antidote to "UN-sustainable development", I would like to launch a slightly different concept here.

We should rediscover the advantages of the "evolutionary and sustainable maintenance" of the territory (a thesis also supported by Marcello Vittorini, one of the greatest Italian urban planners of the twentieth century, as early as the 1980s).

"Rediscover" because, at least until the middle of the twentieth century, the approach to urban settlements and the territory in general has always been of this type: it is modified - or replaced - to adapt the city to the varied living conditions linked to progress. Before expanding the city, at least the traditional and European one, has always adapted the existing heritage, experiencing all the possibilities that transformation offers, with the aim of improving.

From this, the "evolutionary maintenance" consists of a multiplicity of behaviours and actions aimed at adapting existing urban and architectural heritages to the continuous mutation of the needs of society.

Historical centres are the result of sedimentation and reuse and owe their beauty to this continuous process. Process that stops only when people begin to abandon them.

Today, however, there are all the tools and opportunities, including economic ones, to reverse the trend and reactivate historical centres and internal territories. Starting right from the construction sector: the "recovery" of the existing one, its "scheduled and continuous maintenance" are the opportunities for a clearly asphyxiated construction market. And more and more cases of recovery of the building stock of smaller towns are beginning to be registered as an opportunity for building revival. This can be achieved by careful processing of the buildings, to adapt, for example, the need for spaces larger per capita or

10 These themes are studied by two research projects, one for the development of a Historical Small Smart Cities Protocol, which, under my coordination, was also carried out within the framework of a prestigious Marie Curie research grant from Valentina Pica; and the other, interdepartmental, for the definition of a Protocol for the mitigation of natural risks in the minor historical centres of Lazio, which has benefited from a grant from the University (by the Call4Ideas call) and which is coordinated by my colleague and friend Giovanna Spadafora.

11 Latouche explains the meaning of "degrowth" through eight virtuous behaviours, eight goals, the 8 " $R$ ": revaluate, reconceptualize, restructure, redistribute, relocate, reduce, reuse, recycle. 
a hygienic-environmental quality different to energy efficiency and anti-seismic adaptation, operating in a truly smart key.

If, on the other hand, we switch from the construction sector to the fundamental one of transport, we can highlight the opportunities for reactivating public transport in the "peripheral territories", linked precisely to the various "nuances" of the European policies of liberalization of the transport market.

First of all, if we tackle the issue of railways - the most sustainable means of transport - we can maintain certainty that shifting attention from fast lines and large urban centres (few, congested, saturated) to "peripheral territories" (many, widespread and available) is a viable and even profitable option for railway companies that want to deal with an alternative type of service (Mattarocci, Scimone, 2018). This would make it possible to strengthen the territorial armour, progressively rebuilding the system of relationships that are the basis of the Right to Mobility (Amato et al., 2019).

Reactivating "inner areas" and small historical centres therefore means reactivating economic, social, cultural relationships. It means bringing back an active population that can "maintain" the territory as a source of life.

And this should be the central objective of a true "sustainable and inclusive development". 


\section{References}

Amato, C., Ravagnan, C., Rossi, F., Ureña Frances, J. M. (2019). Derecho a la movilidad y rutas de resiliencias: reutilización y relanzamiento de ferrocarriles secundarios para la regeneración de territorios frágiles en Italia y España. [In:] XIII International Conference on Virtual City and Territory: "Challenges and paradigms of the contemporary city" Barcelona: CPSV. http://dx.doi.org/10.5821/ctv.8527

Barca, F., Casavola, P., Lucatelli, S. (2014). Strategia nazionale per le Aree interne: definizione, obiettivi, strumenti e governance. Materiali Uval, no. 31, Roma.

Blečić I., Cecchini A. (2016). Verso una pianificazione antifragile. Come pensare al futuro senza prevederlo. Milano: Franco Angeli.

Cerasoli M. (2010). Il recupero dei centri storici: la "modulazione della tutela". L'esperienza del Piano di Recupero per il Centro Storico di Formello (Roma). [In:] Atti della XIII Conferenza SIU "Città e crisi globale. Clima, sviluppo e convenienza”. Roma, 25-27 Febbraio.

Cerasoli, M., Biere Arenas, R. M. (2016). The sustainable future of the smaller historical centres, between "modulation of the protection" and new technologies. A: Virtual City and Territory. [In:] Back to the Sense of the City: International Monograph Book (pp. 297-312). Barcelona: Centre de Política de Sòl i Valoracions.

Cervellati, P.L. (2009). La sorte dei piccoli centri storici: abbandonati, trasfigurati, turisticizzati. Minori e maltrattati. Bollettino Italia Nostra.

Latouche, S. (2007). Petit traité de la décroissance sereine. Paris: Mille et Une Nuits.

Mattarocci G., Scimone X. (2018). Efficienza delle società ferroviarie a servizio delle aree interne: un'analisi di bilancio. [In:] Atti della XXXIX Conferenza scientifica annuale AISRE. Bolzano (BZ), 17-19 Settembre.

Pica, V. Cerasoli, M. (2018). Protocol of integrated sustainable interventions for historic small smart cities: the mitigation of disaster risk. [In:] Proceedings of the VI International Conference Heritage 2018, Heritage and Sustainable Development. Barcelos, Portogallo: Green Lines Institute for Sustainable Development.

Seassaro, L. (ed.) (1973). Una nuova politica per i centri storici. [In:] Atti del VI Convegno Nazionale ANCSA. Bergamo, 7-9 Maggio. Genova: ANCSA.

Taleb, N.N. (2013). Antifragile. Prosperare nel disordine. Milano: Il Saggiatore.

ISTAT (2014). National Institute of Statistics.

ISTAT (2017). National Institute of Statistics.

ISTAT (2020). National Institute of Statistics. 